\title{
Outcome of Surgical Management in Spontaneous Supratentorial Intracerebral Hemorrhage Patients: A Randomized Control Trial
}

\author{
Mohammad Rafiqul Islam¹, Mohammad Ashraful Haque², Amir Mohammad Khan ${ }^{3}$, \\ Md. Mahfuzur Rahman ${ }^{4}$, Kazi Nur Asfia ${ }^{5}$, Moazzam Hossain Talukder ${ }^{6}$, Abdus Salam$^{7}$
}

\begin{abstract}
${ }^{1}$ Assistant Professor, Department of Neurosurgery, National Institute of Neurosciences \& Hospital, Dhaka, Bangladesh; ${ }^{2}$ Assistant Professor, Department of Neurosurgery, National Institute of Neurosciences \& Hospital, Dhaka, Bangladesh; ${ }^{3}$ Assistant Professor, Department of Neurosurgery, National Institute of Neurosciences \& Hospital, Dhaka, Bangladesh; ${ }^{4}$ Assistant Professor, Department of Neurotrauma, National Institute of Neurosciences \& Hospital, Dhaka, Bangladesh;

${ }^{5}$ Assistant Professor, Department of Anaesthesia, National Institute of Neurosciences \& Hospital, Dhaka, Bangladesh; ${ }^{6}$ Assistant Professor, Department of Neurosurgery, National Institute of Neurosciences \& Hospital, Dhaka, Bangladesh; ${ }^{7}$ Associate Professor, Department of Neurotrauma, National Institute of Neurosciences \& Hospital, Dhaka, Bangladesh
\end{abstract}

[Received: 21 January 2016; Revised: 6 March 2016; Accepted: 11 December 2016; Published: 1 January 2017]

\begin{abstract}
Background: Management of spontaneous supratentorial intracerebral hemorrhage is crucial. Objective: The purpose of the present study was to compare the outcome of surgery in relation to conservative management of spontaneous supratentorial intracerebral hemorrhage. Methodology: This was a single centred, parallel randomized control trial which was conducted in the Department of Neurosurgery at Dhaka Medical College and Hospital from January 2010 to October 2011 for a period of one year and ten months. All hypertensive patients with spontaneous supratentorial intracerebral hemorrhage who were admitted within 48 hours of stroke in Neurosurgery Department during the study period were considered as a study population. Patients underwent surgery was considered as group I and patients those who did not give the consent for operation were treated conservatively was considered as group II. Surgery and conservative groups were matched in age. Result: A total of 31 patients were enrolled in this study. Fourteen (14) patients underwent surgical evacuation while seventeen (17) patients those who didn't give consent for operation were selected for conservative therapy. The distribution of the study patients according to GOS (30 days) that $6(42.9 \%)$ and $10(58.8 \%)$ patients in surgery and conservatively managed patients were dead respectively; however, $4(28.6 \%)$ patients in surgery and $3(17.6 \%)$ patient in conservative group had good recovery. Besides, $2(14.3 \%)$ surgery patients and $3(17.6 \%)$ conservative patients were severe disabled. Moreover, $2(14.3 \%)$ surgery patients and $1(5.9 \%)$ conservative patients were moderately disabled. Conclusion: In conclusion surgical evacuation of spontaneous supratentorial intracerebral hemorrhage has a benefit on outcome compared to conservative medical treatment. [Journal of National Institute of Neurosciences Bangladesh, 2017;3(1): 37-41]
\end{abstract}

Keywords: spontaneous; supratentorial; intracerebral hemorrhage; surgical outcome

Correspondence: Dr. Mohammad Rafiqul Islam, Assistant Professor, Department of Neurosurgery, National Institute of Neurosciences \& Hospital, Dhaka, Bangladesh; Email: drrafiqul_islam@yahoo.com ; Cell No.: 01717083088

Conflict of interest: There is no conflict of interest relevant to this paper to disclose.

Funding agency: This research project was not funded by any group or any institution.

Contribution to authors: Islam MR, Haque MA, Khan AM, Rahman M were contributed from the protocol preparation upto report writing. Islam MR, Asfia KN, Salam A were involved in the manuscript writing and revision.

How to cite this article: Islam MR, Haque MA, Khan AM, Rahman M, Asfia KN, Talukder MH, Salam A. Outcome of Surgical Management in Spontaneous Supratentorial Intracerebral Hemorrhage Patients: A Randomized Control Trial. J Natl Inst Neurosci Bangladesh, 2017;3(1): 37-41

Copyright: (C2017 Islam et al. Published by Journal of National Institute of Neurosciences Bangladesh. This article is published under the Creative Commons CC BY-NC License (https://creativecommons.org/licenses/by-nc/4.0/). This license permits use, distribution and reproduction in any medium, provided the original work is properly cited, and is not used for commercial purposes.

\section{Introduction}

Combining all types of stroke it is the third leading cause of death in adult population i.e. over 40 years of age after ischemic heart disease and cancer in 
developed country and the first leading cause of disability $^{1}$. The high rate of morbidity and mortality has prompted investigations for new medical and surgical therapies for ICH. According to WHO stroke may be defined as rapidly developing clinical signs of focal disturbance of cerebral function, lasting more than 24 hours or leading to death with no apparent cause other than that of vascular origin ${ }^{2}$.

The initial management of all patients with spontaneous ICH consists of acute medical intervention, followed by either surgical or conservative treatment. The goals of acute medical treatment include control of hypertension, reduction of increased intracranial pressure, prevention of seizure and deep venous thrombosis prophylaxis. Elevated blood pressure is seen in 46 to $56 \%$ of patients with $\mathrm{ICH}^{3}$. It remains unclear if elevated blood pressure directly causes hematoma expansion but studies have shown elevated systolic, diastolic, and mean arterial pressure are associated with a poor outcome in $\mathrm{ICH}^{4-5}$.

Proper timing of surgical intervention is also very important. Small hematomas whether superficial or deep are preferably treated best by wait and watch policy ${ }^{6}$. Infratentorial hemorrhages seem to benefit from early surgery. Most neurosurgeons believe cerebellar hemorrhages greater than 3 centimeters benefit from early surgical intervention because of the significant risk of brainstem compression and obstructive hydrocephalus within 24 hours?

In context of Bangladesh, surgical management in certain cases of spontaneous primary ICH (SPICH) group revealed better early outcome of surgery than that of conservative group. As the controversy in the management strategy still remains, "surgically treated patients had just significant outcome in comparison to the conservatively managed group" in $\mathrm{SPICH}^{8}$. In this context this present study was undertaken to compare the outcome of surgery in relation to conservative management of spontaneous supratentorial intracerebral hemorrhage.

\section{Methodology}

Study Population and Settings: This was a single centred, parallel randomized control trial which was conducted in the Department of Neurosurgery at Dhaka Medical College and Hospital from January 2010 to October 2011 for a period of one year and ten months. All hypertensive patients with spontaneous supratentorial intracerebral hemorrhage who were admitted within 48 hours of stroke in Neurosurgery Department during the study period were considered as a study population.
Randomization and Blinding: The study population was divided into two groups designated as group A who were treated with surgical management and group B who were treated conservatively. Patients who didn't give consent for operation were selected for conservative therapy. Prior to commencement of this study, the research protocol was approved by ethical committee. The inclusion criteria of study population were patient admitted within 48 hours of ictus, CT-scan evidence of spontaneous supratentorial ICH, only lobar hematoma was included in this study, hematoma volume more than $30 \mathrm{ml}$ in CT-scan, hematoma causing mass effect like midline shift, GCS score 6 to 12 , age 40 to 70 years and only hypertensive cases were included in this study. The exclusion criteria of study population were patient after 48 hours of ictus, ICH other than spontaneous, posterior fossa (cerebellum) and deep seated (thalamus, putamen) hematoma, hematoma with ventricular extension, GCS score $<6$ and $>12$, patient with co morbid disease as diabetes, ischemic heart disease, COPD and patient taking any anticoagulant (as warfarin) and drugs that inhibit platelet aggregation (as aspirin).

Study Procedure: This study was done on admitted patients with a brain CT scan confirmed spontaneous supratentorial ICH fulfilling all selection criteria. All these patients were evaluated on the basis of detailed history and clinical examination. Surgical treatment: After giving the consent, patients selected for surgical treatment were taken to the operating room as soon as possible. All surgical cases underwent either decompressive craniotomy or craniectomy under general anesthesia. Medical treatment: Medical treatment included osmotherapy, blood pressure control, seizure prophylaxis, deep venous thrombosis prophylaxis, intravenous fluids, $\mathrm{H} 2$ blockers and early nutritional support ${ }^{9}$.

Follow up and Outcome Measures: The patients of both groups were continuously followed up by observing the GCS score at 7th day and 30th days Glasgow outcome scale (GOS). A check list was prepared by the researcher considering the variables such as age, volume of haematoma, GCS and GOS. The check list was tested first in the department of Neurosurgery of Dhaka Medical College and Hospital and then finalized. The data was collected by the researcher himself. On admission, detailed history from the attendants was taken. General and neurological examination of patients was done. Findings of CT scan were recorded carefully. GCS and GOS were also recorded. 
Statistical Analysis: Data was collected and edited manually. A master sheet was prepared and data was analyzed by SPSS (Statistical package for social science). Unpaired $\mathrm{t}$-test, paired $\mathrm{t}$-test, correlation and Chi square $\left(\chi^{2}\right)$ test were performed. The level of significance considered $p$ value $<0.05$. The summarized data was then presented in tabulated form.

\section{Results}

A total of 60 patients having stroke within 48 hours with spontaneous supratentorial ICH were selected. Out of these 29 patients were not included in the study due to unable to fulfill the selection criteria. Fourteen (14) patients underwent surgical evacuation while seventeen (17) patients those who didn't give consent for operation were selected for conservative therapy. Therefore a total of 31 patients were enrolled in this study. The mean \pm SD age were $53.29 \pm 6.92$ years and $52.47 \pm 7.51$ years in surgery and conservative patients respectively. Half of the surgery patients were in between 40 to 50 years of age group. Besides, in conservative patients maximum $7(41.2 \%)$ number was found in both 40 to 50 years and 51 to 60 years. Mean age difference was not statistically significant $(p>0.05)$ (Table 1).

Table 1: Age distribution of the study patients $(n=31)$

\begin{tabular}{lccl}
\hline Age Group & $\begin{array}{c}\text { Surgery } \\
(\mathbf{n = 1 4 )}\end{array}$ & $\begin{array}{c}\text { Conservative } \\
(\mathbf{n = 1 7})\end{array}$ & p-value \\
\hline 40 to 50 Years & $7(50.0 \%)$ & $7(41.2 \%)$ & \\
51 to 60 Years & $5(35.7 \%)$ & $7(41.2 \%)$ & \\
More than 60 Years & $2(14.3 \%)$ & $3(17.6 \%)$ & \\
Mean \pm SD & $53.29 \pm 6.92$ & $52.47 \pm 7.51$ & $0.758^{\text {ns }}$ \\
Range (min-max) & $(45-65)$ & $(40-65)$ & \\
\hline
\end{tabular}

ns = not significant; $P$ value reached from unpaired t-test

Table 2 shows the distribution of the study patients according to type of surgery and observed that craniotomy was $8(57.1 \%)$, craniectomy $6(42.9 \%)$.

Table 2: Distribution of the study patients according to types of surgery done $(\mathrm{n}=14)$

\begin{tabular}{lcc}
\hline Surgery & Frequency & Percentage \\
\hline Craniotomy & 8 & 57.1 \\
Craniectomy & 6 & 42.9 \\
\hline
\end{tabular}

ns = not significant; $\mathrm{P}$ value reached from unpaired t-test

The patients were considered according to GOS (30 days). In this study 6(42.9\%) and $10(58.8 \%)$ patients in surgery and conservatively managed patients were dead respectively; however, $4(28.6 \%)$ patients in surgery and $3(17.6 \%)$ patient in conservative group had good recovery. Besides, 2(14.3\%) surgery patients and
$3(17.6 \%)$ conservative patients were severe disabled. Moreover, 2(14.3\%) surgery patients and 1(5.9\%) conservative patients were moderately disabled (Table 3).

Table 1: Age distribution of the study patients $(\mathrm{n}=31)$

\begin{tabular}{lccc}
\hline GOS (30 days) & Surgery & Conservative & Total \\
\hline Dead & $6(42.9 \%)$ & $10(58.8 \%)$ & 16 \\
Severe disabled & $2(14.3 \%)$ & $3(17.6 \%)$ & 5 \\
Moderate disabled & $2(14.3 \%)$ & $1(5.9 \%)$ & 3 \\
Good recovery & $4(28.6 \%)$ & $3(17.6 \%)$ & 7 \\
Total & $\mathbf{1 4}$ & $\mathbf{1 7}$ & $\mathbf{3 1}$ \\
\hline
\end{tabular}

\section{Discussion}

This comparative study was carried out with an aim to compare the outcome of surgery in relation to conservative management of spontaneous supratentorial intracerebral hemorrhage. A total of 31 patients with spontaneous supratentorial ICH, evaluated by brain CT scan were included in the study, in the Department of Neurosurgery of Dhaka Medical College and Hospital, Dhaka during January 2010 to October 2011. Fourteen patients underwent surgery was considered as group I and 17 patients those who did not give consent for operation were treated conservatively was considered as group II and subsequently followed up by monitoring GOS (at 30 days).

In this present study it was observed that the mean $\pm \mathrm{SD}$ age was $53.29 \pm 6.92$ years and $52.47 \pm 7.51$ years in surgery and conservative group respectively, which was almost similar between two groups, no statistical significant $(\mathrm{p}>0.05)$ difference was observed. A half $(50.0 \%)$ of the surgery patients were in $5^{\text {th }}$ decade. Besides, in conservative group maximum (41.2\%) patients were found in $5^{\text {th }}$ and 6th decade. Similarly, Mourad et $\mathrm{al}^{9}$ have observed the mean age of the patients having spontaneous supratentorial ICH was $56.65 \pm 11.47$ years in surgery group and $49.60 \pm 15.28$ years in conservative group and the difference was not statistically significant $(\mathrm{p}>0.05)$, thus support the present study. Whereas in Bangladesh, Tarikul ${ }^{10}$ has shown mean age was 55.70 years and in Pakistan, Ahmed et $\mathrm{al}^{11}$ have shown the mean age was 58.8 years in patients having spontaneous intracerebral hemorrhage, which is comparable with the current study.

Craniotomy was done by Sun et $\mathrm{al}^{12}$, Mendelow et $\mathrm{al}^{13}$, Prasad et $\mathrm{al}^{14}$ and Pantazis et $\mathrm{a}{ }^{15}$. In another study, Broderick et al ${ }^{16}$ recommended that craniotomy has been the standard approach for removal of ICH. Its major advantage is adequate exposure to remove the clot. More complete clot removal may decrease 
elevated ICP and local pressure effects of the blood clot on the surrounding brain mentioned by Broderick et $\mathrm{a}^{16}$. The major disadvantage is that it may lead to further brain damage. In this study it was observed that craniotomy was done in more than a half $(57.1 \%)$ of the patients and craniectomy was done in $42.9 \%$ of the patients. Similarly, Rahman ${ }^{17}$ and Tarikul ${ }^{10}$ showed craniotomy was more common in their study, whereas craniectomy were done $24.0 \%$ and $10.0 \%$ respectively, which are comparable with the current study.

According to GOS in this current series it was observed that $42.9 \%$ surgery patients and $58.8 \%$ conservative treatment patients were dead. Auer et al (1989) reported mortality rate of $42.0 \%$ in the surgical group and $80.0 \%$ in the medical group but their follow up duration was six months. Similar mortality rate was also made by Teernstra et $\mathrm{a}^{18}$ (56\% in surgery and $59 \%$ in medical group), Pantazis et $\mathrm{al}^{15}$, Miller et $\mathrm{al}^{19}$ and Zuccarello et $\mathrm{al}^{20}$. In Bangladesh Barkatulla ${ }^{8}$ found mortality rate $38.8 \%$ and $73.2 \%$ in surgery and conservative group respectively. But Kurtsoy et $\mathrm{al}^{21}$ showed mortality was $14.3 \%$ in surgery and $50 \%$ in conservative group. Their low mortality in surgery group may be due to early evacuation of clot within 24 hours. Rahman ${ }^{17}$ showed $17.2 \%$ and $22.2 \%$ in surgery group and conservative treatment group respectively, which was higher in conservative group. All these investigators have observed higher mortality rate in patients who received conservative treatment, which is consistent with the present study. On the other hand in this current study, it was observed that $28.6 \%$ and $17.6 \%$ patients had good recovery in surgery and conservative group respectively, which is similar with Rahman ${ }^{17}$. Besides, $14.3 \%$ in surgery and $17.6 \%$ in conservative patients were severe disabled. Moreover, $14.3 \%$ surgery patients and $5.9 \%$ conservatively managed patients were moderately disabled. No significant $(\mathrm{p}>0.05)$ difference was found between two groups. These results agreed with Morgenstern et $\mathrm{al}^{22}$, where Good outcome (good recovery or moderate disability on the Glasgow outcome scale) was significantly better in those treated with surgery, but there was no difference in overall survival.

\section{Conclusion}

This study concludes that surgical evacuation of spontaneous supratentorial intracerebral hemorrhage has a benefit on outcome compared to conservative medical treatment. Death occurs more in the conservative than surgical group. Furthermore good recovery is found in the surgical group over conservative group. Further large scale study should be carried out to see the real scenario.

\section{References}

1. Allen CMC, Lueck CJ. Diseases of the nervous system. In: Haslette C, Chilvaers ER, Unter JAA, Roon NA. Davidson's principles and practice of medicine. 21st ed. Newdelhi: Churchill Living Stone, 2010;1203-05

2. Hatano S. Experience from multicentre stroke register: A Preliminary Report Bull WHO, 1976;54:541-53

3. Dandapani BK, Suzuki S, Kelley RE, Reyes-Iglesias Y, Duncan RC. Relation between blood pressure and outcome in intracerebral hemorrhage. Stroke. 1995;26(1):21-4

4. Leonardi-Bee J, Bath PM, Phillips SJ, Sandercock PA. Blood pressure and clinical outcomes in the International Stroke Trial. Stroke. 2002;33(5):1315-20

5. Vemmos KN, Tsivgoulis G, Spengos K, Zakopoulos N, Synetos A, Manios E, Konstantopoulou P, Mavrikakis M. U $\square$ shaped relationship between mortality and admission blood pressure in patients with acute stroke. Journal of internal medicine. 2004;255(2):257-65

6. Jha AN. Spontaneou inracerebral hemorrhage. In: Ramamurti B, Tandon PN, Texbook of Neurosurgery. 2nd ed. New Delhi: Churchill Livingstone; 1996;695-705

7. Ott KH, Kase CS, Ojemann RG, Mohr JP. Cerebellar hemorrhage: diagnosis and treatment: a review of 56 cases. Archives of neurology. 1974;31(3):160-7

8. Barkatullah AM. Role of surgery in the management of primary spontaneous intracerebral hemorrhage in adult patient. [MS Neurosurgery Thesis]. University of Dhaka, 2001

9. Mourad HS, Enab AA, Abdelalim AM. Early outcome of Conservative versus Surgical Treatment of Spontaneous Supratentorial Intracerebral Hemorrhage. Egypt J Neurol Psychiat Neurosurg. 2011;48:85-92

10. Tarikul I. Analysis of early outcome of surgery in spontaneous primary intracerebral haemorrahage in relation to preoperative Glasgow coma scale. [MS Neurosurgery Thesis], University of Dhaka, 2011

11. Ahmed R, Shakir AH, Moizuddin SS, Haleem A, Ali S, Durrani K, Khan A, Baig S. Predictors of in-hospital mortality for intracerebral hemorrhage: a hospital-based study in Pakistani adults. Journal of Stroke and Cerebrovascular Diseases. 2001;10(3):122-7 12. Sun DT, Tsang YY, Poon WS. Intracerebral haematoma: Operative versus non-operative. Surgical Practice. 2004;8(2):55-8 13. Mendelow AD, Gregson BA, Fernandes HM, Murray GD, Teasdale GM, Hope DT, Karimi A, Shaw MD, Barer DH, STICH investigators. Early surgery versus initial conservative treatment in patients with spontaneous supratentorial intracerebral haematomas in the International Surgical Trial in Intracerebral Haemorrhage (STICH): a randomised trial. The Lancet. 2005;365(9457):387-97 14. Prasad KS, Gregson BA, Bhattathiri PS, Mitchell P, Mendelow $\mathrm{AD}$. The significance of crossovers after randomization in the STICH trial. Brain Edema XIII. 2006:61-4

15. Pantazis G, Tsitsopoulos P, Mihas C, Katsiva V, Stavrianos V, Zymaris S. Early surgical treatment vs conservative management for spontaneous supratentorial intracerebral hematomas: a prospective randomized study. Surgical neurology. 2006;66(5):492-501

16. Broderick J, Connolly S, Feldmann E, Hanley D, Kase C, Krieger D, Mayberg M, Morgenstern L, Ogilvy CS, Vespa P, Zuccarello M. Guidelines for the Management of Spontaneous Intracerebral Hemorrhage in Adults: 2007 Update A Guideline From the American Heart Association/American Stroke Association Stroke Council, High Blood Pressure Research Council, and the Quality of Care and Outcome [J]. Chinese Journal of Cerebrovascular Diseases (Electronic Version). 2008;1:018

17. Rahman A. Comparative study between outcomes of patients 
of supratentorial spontaneous intracerebral haematoma treated conservatively and surgically. [MS Neurosurgery Thesis], University of Chittagong, 2008

18. Teernstra OP, Evers SM, Lodder J, Leffers P, Franke CL, Blaauw G. Stereotactic treatment of intracerebral hematoma by means of a plasminogen activator. Stroke. 2003 Apr 1;34(4):968-74.

19. Miller CM, Vespa P, Saver JL, Kidwell CS, Carmichael ST, Alger J, Frazee J, Starkman S, Liebeskind D, Nenov V, Elashoff R. Image-guided endoscopic evacuation of spontaneous intracerebral hemorrhage. Surgical neurology. 2008;69(5):441-6

20. Zuccarello M, Brott T, Derex L, Kothari R, Sauerbeck L, Tew
J, Van Loveren H, Yeh HS, Tomsick T, Pancioli A, Khoury J. Early surgical treatment for supratentorial intracerebral hemorrhage. stroke. 1999;30(9):1833-9.

21. Kurtsoy A, Oktem IS, Koc RK, Menku A, Akdemir H, Tucer B. Surgical treatment of thalamic hematomas via the contralateral transcallosal approach. Neurosurgical review. 2001;24(2):108-13 22. Morgenstern LB, Hemphill JC, Anderson C, Becker K, Broderick JP, Connolly ES, Greenberg SM, Huang JN, Macdonald RL, Messé SR, Mitchell PH. Guidelines for the management of spontaneous intracerebral hemorrhage. A guideline for healthcare professionals from the American Heart Association/American Stroke Association. Stroke. 2010 Jul 22 